\title{
GAS TURBINE COMBUSTOR WITH INTEGRATED ASH REMOVAL FOR FINE PARTICULATES
}

\author{
Caroline Syred \\ Cardiff University, UK
}

\author{
Anthony Griffiths \\ Cardiff University, UK
}

\author{
Nick Syred \\ Cardiff University, UK
}

\begin{abstract}
This paper examines the performance of a novel design of combustor for utilising variable calorific value fuel gases as produced by many biomass gasification processes. An integral ash removal system is incorporated into the combustor to reduce the need for subsequent hot gas or other cleanup systems. The combustor is of cyclonic design with tangential inlets for air, start-up fuel and gasification products. Flame stability for low calorific value gases can be enhanced via the use of ceramic/refractory lined sections if required, with the system operating under lean combustion at all times to minimise NOx. Pressure drop of the cyclonic system is minimised by the use of a tangential outlet, as are combustion instabilities, as large central recirculation zones are avoided and associated instabilities like the precessing vortex core.

Ash removal from the system is important to minimise damage to turbine components. Two regions are used for particle removal. The first is the base of the unit of a conventional hopper design, and the other, a unique vortex collector pocket (VCP) carefully positioned by the tangential off-take to take advantage of the accelerating tangential flow into the off-take.

This paper focuses on the use of CFD to optimise the combustion performance of the combustor run under different operating conditions as well as the removal of coarse and fine material from the flow.
\end{abstract}

\section{Keywords: Cyclone Combustor, LCV biomass gas}

\section{INTRODUCTION}

One of the major problems arising from the use of gasified products from biomass in small gas turbines is the development of stable secondary combustors which can efficiently utilise the variable quality, medium to low calorific value gases produced whilst still be capable of efficiently utilising fuels such as heating oil or natural gas for start-up/shutdown operations or as a pilot fuel during certain operational periods. A further requirement in direct-fired gas turbine applications is the removal of as many particles as possible down to 5 microns or less to minimise damage to the turbine.

A cyclone type combustor was designed for such a process and will run on multiple fuels, primarily oil and low to medium $\mathrm{CV}$ wood gas. Three-dimensional CFD modelling of the combustor was performed using the package Fluent 6 . The model was run using low to medium $\mathrm{CV}$ wood gas under different inlet configurations. The flow characteristics and temperature patterns in the combustor were investigated as well as the ash removal from the system.

The wood gas entering the combustor contained particles of varying size. The combustor was designed with a conical bottom to collect larger particles, however it was known that finer particles would still be carried with the flow to the combustor exit. A VCP positioned just before the tangential off take was installed to collect the finer particles before they exit the combustor. This would remove the need for the use of a cyclone separator after the combustor to remove the finer particles, which would create an extra pressure drop to the system. The pressure drop across the system also needs to be minimised to ensure efficient operation. The CFD modelling enabled the performance of the VCP to be assessed and optimised so that it removed particles to below the turbine specification for all operating conditions.

This paper describes the design of the cyclone type combustor capable of burning a variety of fuels with varying low calorific value (LCV) for firing a small gas turbine. Although there are many combustors that are successfully fired on fossil fuels there are few that are capable of operating on multiple fuels and LCV gas. There are a number of problems associated with the effective combustion of medium to low CV gas, including flame stability and varying calorific values. Problems also occur when using dual fuel systems (and with system oscillations) in maintaining a steady flame when changing over fuels. A literature review of dual fuel combustors is discussed in the following section followed by the design and modelling of the cyclone type combustor. 


\section{DEVELOPMENT OF LCV COMBUSTORS FOR GAS TURBINES}

Several studies have been undertaken to develop LCV gas turbine combustors. Problems encountered are numerous and include:

- Generation of non-premixed or diffusion flame to exclude the danger of flashback.

- Maintaining high efficiencies whilst giving low $\mathrm{NO}_{\mathrm{x}}$ and $\mathrm{CO}$.

- The necessity of using larger fuel nozzles and swirlers to handle the higher fuel gas volume

- Issues of fuel quality restrictions such as hydrogen content, particulates, alkalis, heavy metals, tars, fuel gas temperature etc

- The issue addressed in this paper of redesigning the combustor to avoid any drop in efficiency by essentially increasing available residence time, whilst simultaneously dealing with the contaminants in the LCV gas

There is a wide range of work in this area as discussed in references 1 to 6 where the issues raised above are more fully discussed.

An example of a combustor and dual fuel nozle, capable of burning cleaned gasifier generated low heating value gas, as well as diesel fuel is described in reference 7 . The combustion system was based on a conventional combustor can with normal air distribution and aerodynamic pattern. Discrete coaxial jets with air blast liquid fuel atomisation and a combination of swirl and plain orifice low heating value gas fuel injection with a passive air purge arrangement was used. Figure 1 shows a schematic of the dual fuel injector and Figure 2 shows the combustion system. The fuel injector designed had a large volume LBTU gas fuel passage that was open to the hot gas environment which would inevitably cause hot gas recirculation. A passive purge arrangement was used where compressor delivery air is aerodynamically driven to purge the LBTU gas injector. This system was installed in a 4.2 MW gas turbine which forms part of a $15 \mathrm{MW}$ integrated gasification combined cycle heat and power generation technology demonstrator plant in Sweden.

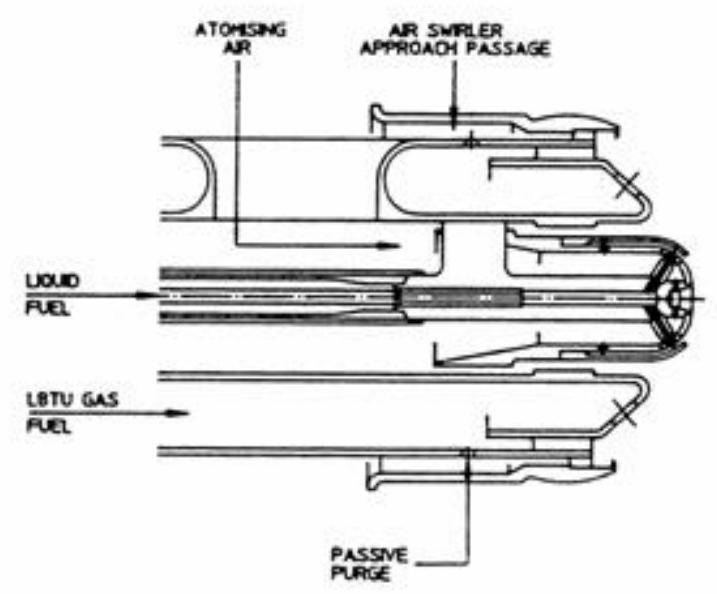

Figure 1: Dual Fuel Injector [7]
The use of LCV gas to achieve the same power output as conventional diesel fuel results in lower flame temperatures and increased fuel flow rates. These factors can affect the flame stability, low power combustion efficiencies and require design attention. The combustion system demonstrated that the lean flame stability limit for both diesel and LBTU gas fuels were adequate to cover the entire engine operating range and fuel change over requirements.

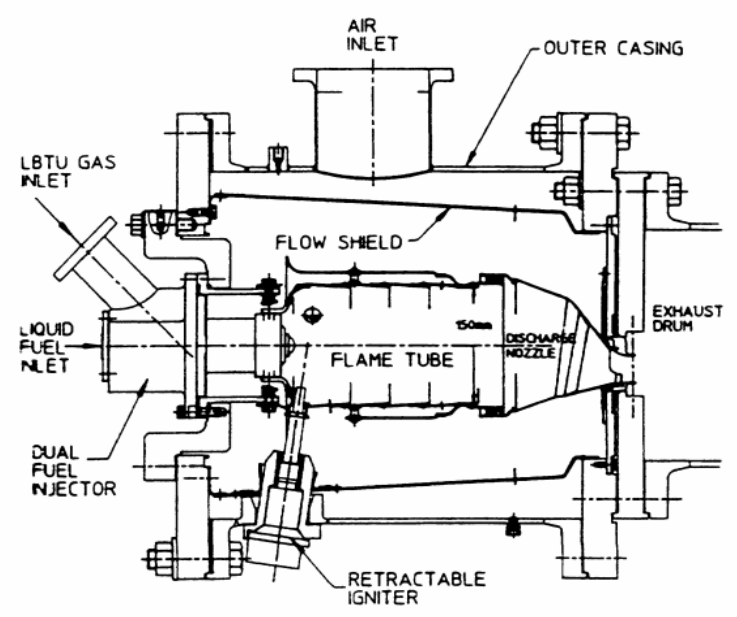

Figure 2: Combustion Test Rig [7]

A major consideration in the design of conventional gas turbine combustors is the fuel nozzle. The nozzle system needs to allow two types of fuels to be introduced to the combustor, the start-up fuel and the LCV biomass fuel. The design should allow the start-up fuel to be phased out as the system is switched to run on the biomass gas once stabilised. This change over of gas should have minimal effect on the gas turbine operation. A dual fuel nozzle system enabling both fuels to be introduced to the comb ustor by the same nozzle was developed [8]. The system should allow a fuel change over from starting fuel to biomass fuel with no effect on gas turbine operations. An existing dual fuel nozzle concept was modified for the use of biomass gas. The existing gas turbine, LM2500 General Electric engine, operated on natural gas and liquid fuel was modified to run on gasified biomass with a number of alterations. The swirler bore was enlarged and shown to have no impact on the combustion performance. Figure 3 and 4 shows the combustor with the biomass fuel nozzle. More detailed information on the gas turbine modifications for biomass fuel operation can be found in the literature and shows a range of fuel nozzles that have been designed for a variety of gas and liquid fuels as well as for LBTU fuel $[8,9]$. The lower fuel heating value (LFHV) was known to impact on the system blow off limits. An indicator of the fuels ability to successfully burn is the percentage of $\mathrm{H}_{2}$ and $\mathrm{CO}$ combustibles in the fuel, if the sum exceeds $80 \%$ and the LFHV is in excess of $3.72 \mathrm{~J} / \mathrm{m}^{3}$, combustion can be sustained in the combustor for all power levels. A $50 \%$ reduction in $\mathrm{NO}_{\mathrm{x}}$ emissions could be expected with the biomass fuel, compared to natural gas operating at maximum power. Gasified biomass gives lower flame temperatures owing to the larger flow rates giving rise to more distributed combustion and uniform temperatures with reduced 
$\mathrm{NO}_{\mathrm{x}}$. However $\mathrm{CO}$ emissions are likely to increase very significantly at full power on biomass fuel. This may require emission improvements such as exhaust stack scrubbing. Higher combustor exit temperatures and lower combustor pressure drops may be a cause of concern for the high-pressure turbine hot section. These high temperatures may be suppressed by larger fuel flow rates, but the pressure drop could affect the turbine blades and nozzle cooling. This might affect the service time of the hot section.

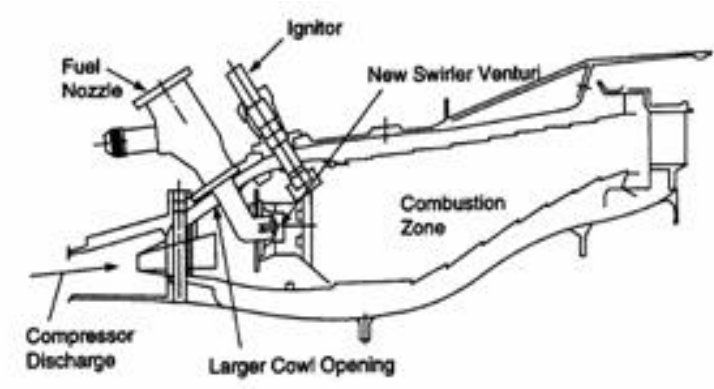

Figure 3: Annular combustor with large swirler and biomass fuel nozzle [8]

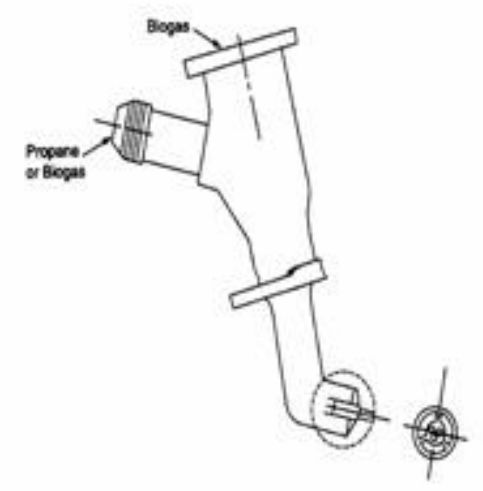

Figure 4: Biomass fuel nozzle configuration [8]

\section{FUEL NOZZLE PERFORMANCE}

The performance of the fuel nozzle is affected by several different parameters, namely emissions, flame stability and combustor liner and fuel nozzle temperatures. Designs either use single fuel nozzles or larger combustors use multiple nozzles. The effects of different low heating value fuel nozzles on these parameters have been investigated [10]. Development of low heating value fuel nozzles have been made since the 1970's [11,12,13,14]. These investigations primarily concentrated on single nozzle gas turbine combustors, with further development needed to implement these nozzles in multiple fuel nozzles. More recently Battista et al. studied the performances of low heating value fuel nozzles designs [10]. Six nozzle configurations were investigated and cover three distinct nozzle concepts. The nozzles produce swirl stabilised diffusion flames with similar axial distribution of fuel/air ratio.
Tests were performed in a modified GE MS6000 combustor liner at successful operating pressures of 10 bar with a wide load range.

Emissions were measured from the combustor for the different fuel nozzles. The conversion trend of $\mathrm{NH}_{3}$ to $\mathrm{NO}_{\mathrm{x}}$ was similar for each nozzle, this is probably caused by the axial distribution of the fuel to air ratio being kept constant for each nozzle. The $\mathrm{NO}_{\mathrm{x}}$ emissions generally decrease as the combustor exit temperature increases. The end of the combustor becomes increasingly fuel rich as the exit temp increases and $\mathrm{NH}_{3}$ is converted to $\mathrm{N}_{2}$ and $\mathrm{H}_{2} \mathrm{O}$. The unburned hydrocarbon (UHC) emissions tend to increase with decreasing combustor exit temperatures. The differences in the UHC emission could not easily be identified between the different nozzles due to the low values ( 2ppmv) being measured. $\mathrm{CO}$ emissions showed significant variations between nozzle types. The $\mathrm{CO}$ emissions increased rapidly as the combustor exit temperature decreased and the combustor approached blow out. For most nozzles blow out occurred below $760^{\circ} \mathrm{C}$. It was found that swirl had a significant effect on the emissions. As the fuel nozzle swirl was increased the $\mathrm{CO}$ emissions decreased and flame stability and turndown increased, however the higher swirl nozzles produced unacceptable liner temperatures. These results show the best nozzle design has concentric axial and radial air and fuel swirlers and an air cooled mixing cup which can perform well as a single nozzle or at large scale as multiple nozzles and for a range of LCV fuels. Similar nozzles to the N7A have given acceptable performance for multi nozzle systems for low to moderate temperature $\mathrm{LCV}$ fuel derived from air blown gasification.

Another combustor development programme was undertaken at British Coal and European Gas turbines [15]. LCV coal derived fuel gas was burnt at high turbine inlet temperatures. A gas turbine combustor was produced that was designed for LCV coal derived fuel gas with high turbine inlet temperatures and minimum pollutant effects. The combustor design gave high combustion efficiencies, greater than $99 \%$, with uniform outlet temperature profiles and low combustion metal temperatures. Low $\mathrm{NO}_{\mathrm{x}}$ emissions were also achieved.

The development of biomass power generation is discussed in the literature and investigates the problems associated with the process, and the modifications required to the gas turbine to accept hot low energy gas [16]. A small scale (>1 MW) biomass plant is been developed which can run on LCV biomass fuel. A pressurized air blown fluid bed reactor with fuel injection from a pressurised and metered biomass unit is used. Modifications have been made to the combustor, with diesel as the start up fuel. It is expected that the diesel can be completely shut off and the turbine run completely on the LCV biomass fuel.

\section{EVALUATION OF DESIGNS}

All these designs are essentially derived from conventional gas turbine combustor systems fired on conventional liquid fuels or natural gas. They are all designed to be fired on cleaned bio-gas, this arises from the type of turbine equipment used with sophisticated turbine blades incorporating numerous fine cooling passages susceptible to blockage. Conversely this paper addresses a different problem involved with small-scale power systems. Here gas turbine systems are generally of simpler construction with un-cooled turbine blades and can sustain 
modest levels of fine particulates less than 5 microns in size. Indeed some small turbine systems are derived directly from turbochargers. Turbine inlet temperatures are up to $900^{\circ} \mathrm{C}$. To raise efficiency in commercial systems the use of exhaust gas regenerators is necessary to use the turbine exhaust gas enthalpy to preheat the compressor air before it enters the combustor. This work is thus part of a much larger programme to develop a biomass direct fired power system whereby biomass is efficiently gasified then burnt in the combustor described here and fine particles removed by a series of cyclone type devices, a final target being no particulates greater than 5 microns in the combustor exhaust gas. Low pressure drop across the system, low emissions and good stabilisation are also necessary requirements of the system.

\section{COMBUSTOR DESIGN}

The cyclone type combustor is designed with several tangential inlets as shown in Figure 5, two air inlet, a high CV fuel inlet for oil or natural gas and a low CV gas inlet. Tests on a prototype combustor showed the tangential inlets create a strongly swirling flow that gives good mixing and burn out rates. The combustor is to be operated at a maximum thermal input of $500 \mathrm{~kW}$. The combustor is mounted vertically and has a cone section at the base to collect larger particles in the flow. The combustor is designed with a long chamber to allow the flame to move up and down with varying thermal input and quality whilst giving sufficient residence time for fuel burnout and thus low emissions of $\mathrm{CO}$ and volatile hydrocarbons. The central section of the combustor is refractory lined allowing substantial heat storage capacity helping to create stable flames, whilst allowing wall temperatures to be significantly higher than normally accepted in such combustors. Part of the work was investigating how long the refractory section needed to be. There is also a tangential off take on the combustor that recovers energy from the flow and also forces the exhausting flow tangentially across a VCP aperture, hence increasing separation capability. A further advantage lies in its suppression of significant occurrence of coherent structures such as the precessing vortex core $[19,20]$. The combustor is to be used to fire a small gas turbine operating at an inlet temperature of $800^{\circ} \mathrm{C}$, which later will be extended to $900^{\circ} \mathrm{C}$. The exhaust gas of the combustor has higher temperatures than this, and is diluted by a co-flowing air stream that is passed through a jacket surrounding the combustor. This co-flow air lowers the temperature of the exhaust gas and acts as a diffuser to the flow, lowering the pressure drop across the combustor. The VCP is placed just before the tangential off-take which removes fine particle above 5 microns which if carried through the exhaust could damage the turbine. The VCP also removes the need for a cyclone separator to remove the particles, which would increase the pressure drop across the system further.

\section{CFD MODELLING}

The combustor was modelled using the CFD package Fluent 6, under atmospheric conditions but with velocities representative of those occurring under pressurised gas turbine operating conditions. An unstructured, hexadredal, three dimensional grid was applied for this analysis. A finer mesh was concentrated around the inlet and outlet sections. The design of the combustor is shown in Figure 5.

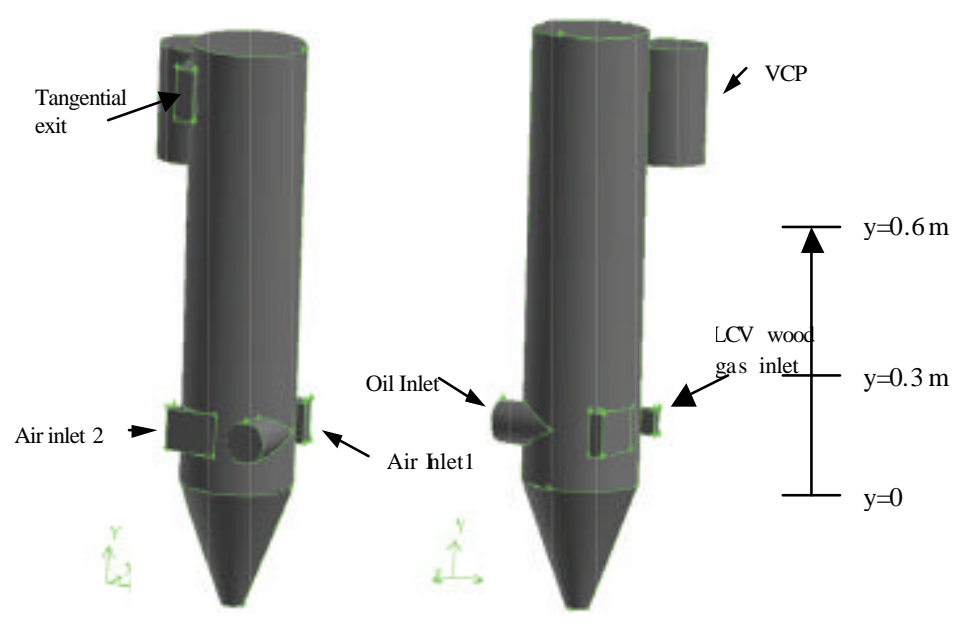

Figure 5: Design of the cyclone type combustor with VCP

The Reynolds Stress turbulence model was used $\$$ the combustor has strong swirling flow. Experience has shown that this model predicts swirling flow with significantly more accuracy than other models [17]. The LCV gas species and gas oil were modelled in Fluent using the mixture fraction/pdf approach thus assuming chemical equilibrium. The local thermo-chemical state is also related to enthalpy as well as the mixture fraction. Table 1 shows the gas composition used for the modelling. Twelve species were defined in the pdf approach.

Table 1: Composition of LCV gas

\begin{tabular}{l|l|l|l|l|l|l|l} 
Species & $\mathrm{H}_{2}$ & $\mathrm{O}_{2}$ & $\mathrm{~N}_{2}$ & $\mathrm{CH}_{4}$ & $\mathrm{CO}$ & $\mathrm{CO}_{2}$ & $\mathrm{H}_{2} \mathrm{O}$ \\
\hline $\begin{array}{l}\text { Mole } \\
\text { fract. \% }\end{array}$ & 5.45 & 1.14 & 47.41 & 1.54 & 9.54 & 11.49 & 23.43
\end{tabular}

The system was assumed to be non-adiabatic as radiative heat transfer to wall boundaries would have to be considered. The Discrete Transfer Radiation Model (DTRM) was used throughout the calculation to account for this heat loss. Heat transfer through the wall boundaries was allowed for with boundary conditions pertaining to those in the gas turbine. Particles were introduced into the LCV gas stream using the discrete phase function. This enables the particles to interact with the flow and predict particle trajectories, hence separation.

\section{COMBUSTOR TESTS}

The combustor was tested with different inlet configurations, thermal inputs and equivalence ratios. The inlet section has four tangential inlets. Two air inlets, a wood gas and an oil inlet. Different combinations of air inlets were used with LCV gas supplied through the wood gas inlet. All of the tests below use $100 \%$ LCV gas supplied through the wood gas inlet. The configuration of the inlet section is shown in Figure 5 (Previous CFD combustor tests have shown the combustor can successfully run on oil and a combination of oil and LCV gas whilst maintain steady combustion and uniform outlet conditions [18]). The inlet configuration, thermal inputs and equivalence ratios for the different tests are shown in Table 2. 
Table 2: Combustor test configuration

\begin{tabular}{l|l|l|l|l}
$\begin{array}{l}\text { Equivalence } \\
\text { ratio }\end{array}$ & $\begin{array}{l}\text { Air Inlet } \\
1(100 \%)\end{array}$ & $\begin{array}{l}\text { Air Inlet } \\
2(100 \%)\end{array}$ & $\begin{array}{l}\text { Air Inlet 1 } \\
(50 \%) \& 2 \\
(50 \%)\end{array}$ & $\begin{array}{l}\text { Thermal } \\
\text { Input kW }\end{array}$ \\
\hline 1.2 & Test 1 & Test 2 & Test 3 & 500 \\
\hline 1.5 & Test 4 & Test 5 & Test 6 & 500 \\
1.5 & Test 7 & Test 8 & Test 9 & 350
\end{tabular}

Fluent models were run for all the test cases and the aerodynamics and combustion characteristics investigated. Typical axial velocity contours taken across the combustor are shown in Figure 6 for test 4.

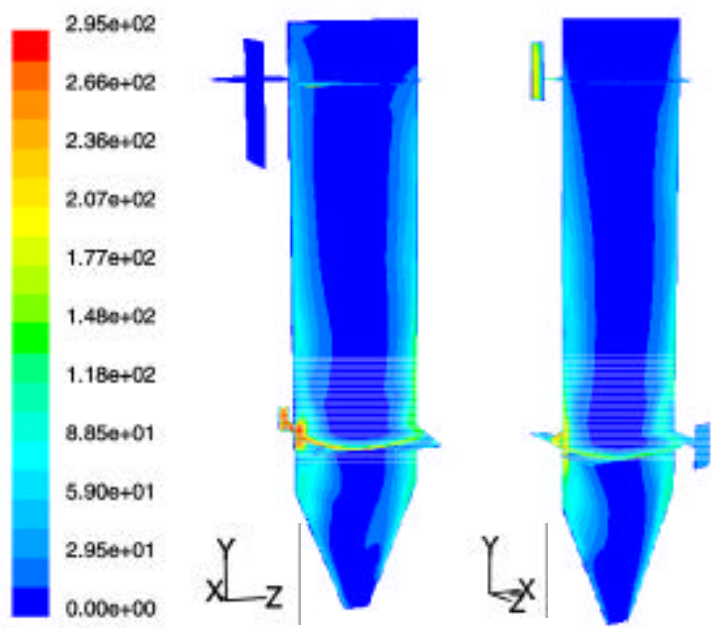

Figure 6: Velocities contours across combustor for test 4

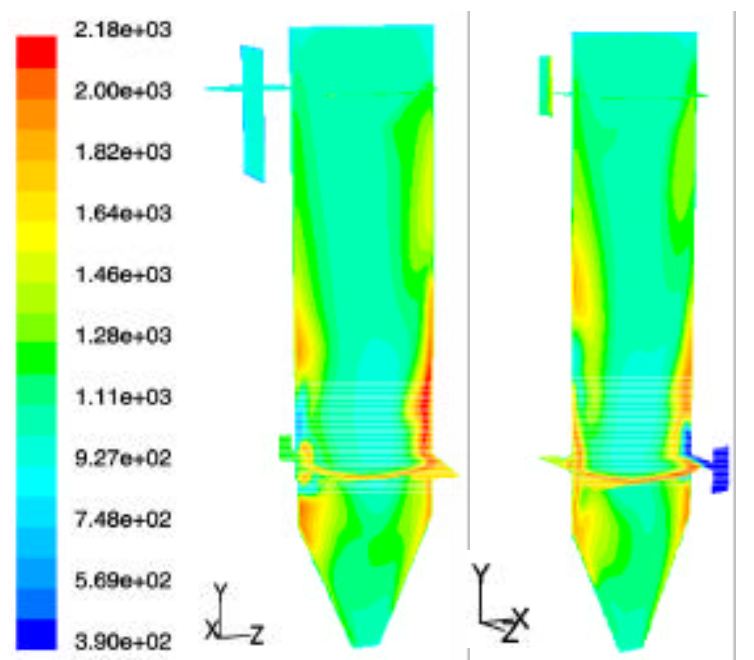

Figure 7: Temperature contours across combustor for test 4

The tangential inlet creates a strongly swirling flow with high tangential velocities near the walls. The tangential velocity decreases towards the centre of the combustor chamber and a forced vortex is formed. This vortex continues along the chambers length. There was evidence of a secondary wall flow into the bottom hopper section, however upwards velocities were small in the central region and the discrete phase particle tracking discussed later showed no evidence of significant numbers of particles being convected into this region, its main function being to catch larger particles, the VCP the smaller fractions.

Static temperature contours across the combustor for test 4 are shown in Figure 7. High static temperatures are located near the combustor wall and correspond to area of high velocity. Lower temperatures are found in the centre of the chamber where low velocities are located. Clearly the high LCV gas velocity is producing efficient mixing of the fuel and air, promoting early combustion and good flame stability. As the flow moves downstream, temperatures across the centre of the chamber increase. Temperature and velocity contours show the combustor has good mixing and burnout.

Axial velocity, temperature and $\mathrm{CO}$ mass fraction profiles have been plotted across the combustor at the beginning of the central refractory section $(\mathrm{y}=0.3 \mathrm{~m})$ and just before the end of the refractory section $(y=0.6 \mathrm{~m})$, Figures 8 to 13 . This will enable the mixing, aerodynamics and inlet configurations of the different case to be examined. Figure 5 shows the position of $\mathrm{y}=0.3$ and 0.6 across the combustor.

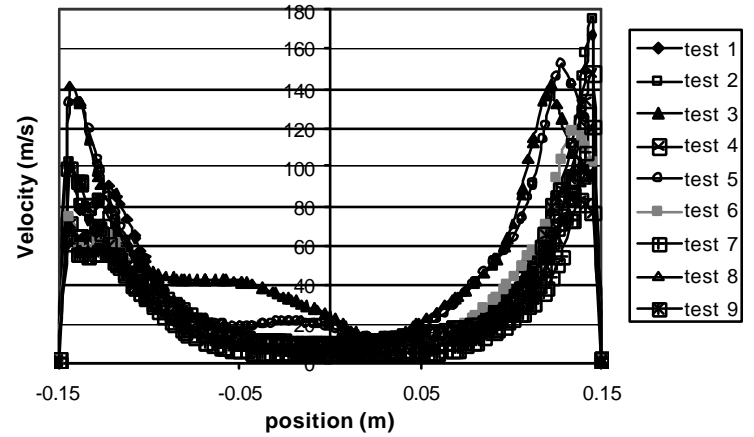

Figure 8: Axial velocity profiles through combustor at $\mathrm{y}=0.3$

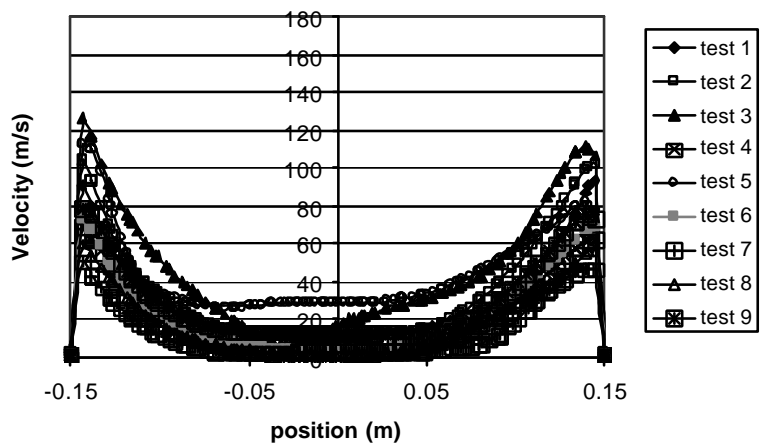

Figure 9: Axial velocity profiles through combustor at $y=0.6$ 


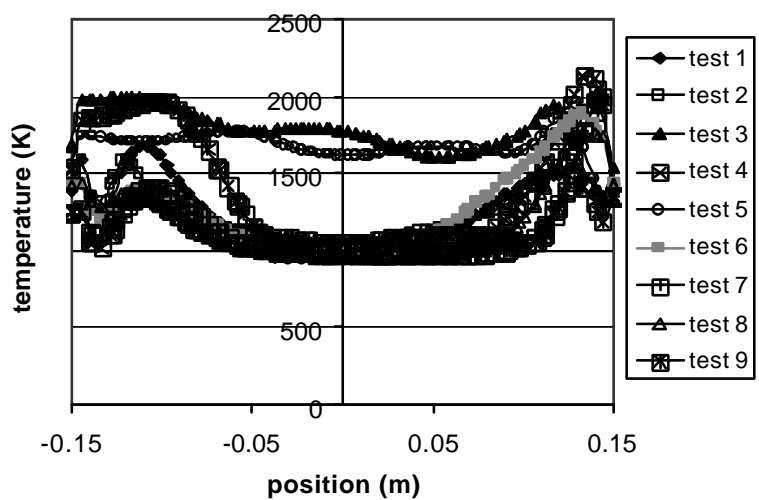

Figure 10: Temperature profiles through combustor at $\mathrm{y}=0.3$

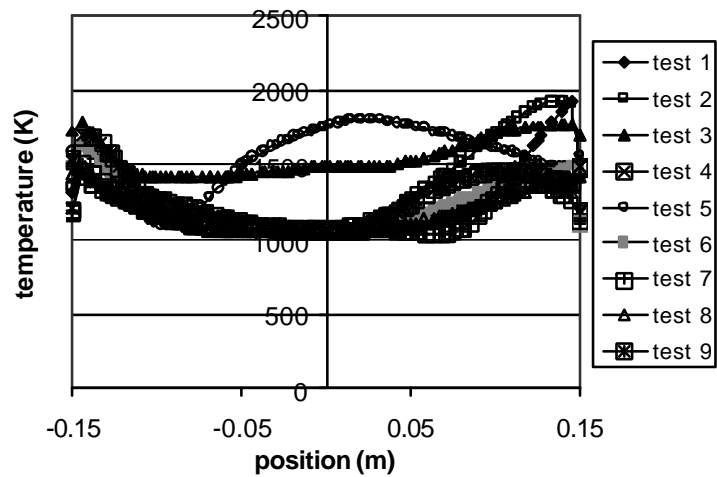

Figure 11: Temperature profiles through combustor at $\mathrm{y}=0.6$

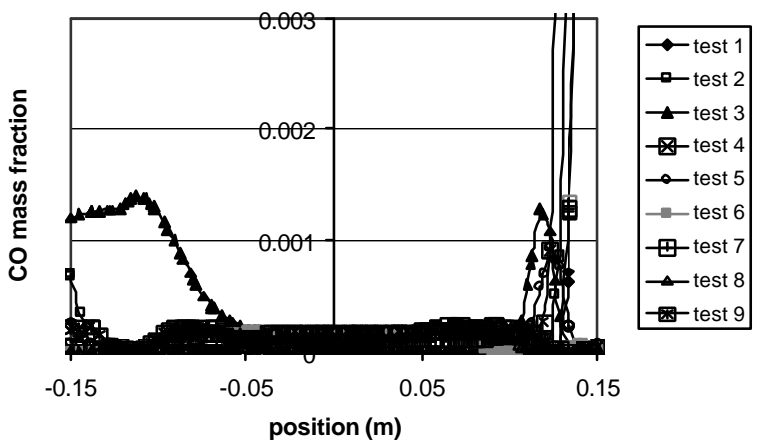

Figure 12: CO mass fraction profiles through combustor at $\mathrm{y}=0.3$

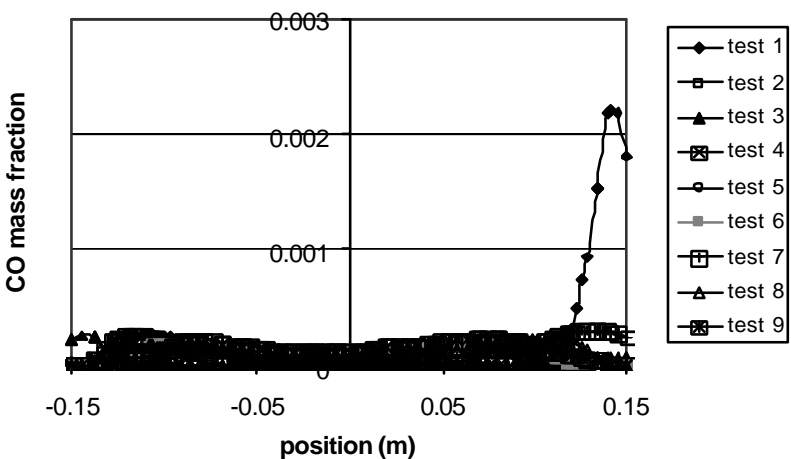

Figure 13: CO mass fraction profiles through combustor at $\mathrm{y}=0.6$
Figures 8 and 9 show that high velocities are maintained near the combustor walls with much lower velocities across the centre where the central vortex is located. At $y=0.3$ central velocities are very low and increase towards the walls. At $y=0.6$ the velocity of the flow across the chamber have decreased slightly. Tests 3 and 5 have highest velocities across the chamber. Temperature profiles at $\mathrm{y}=0.3$ and 0.6 shows similar temperatures across the centre of the combustor for most tests. Tests 3 and 5 have higher temperature across the combustors centre and correspond to the high velocities in these regions. All tests show high temperatures near to the wall and coincide with the regions of high velocities. Most wall temperatures within the primary combustion zone are around $1500 \mathrm{~K}$ or less, Figures 10 and 11. This is an acceptable value as this section of the combustor wall is refractory lined and can with stand these temperatures. Differences in wall temperatures however occur when different air inlet configurations are used, especially at lower air to fuel ratio's. Test 3 has the highest wall temperatures at approximately $1700 \mathrm{~K}$. This test splits the air equally between inlet 1 and 2, and has a lower air to fuel ratio than tests 4 to 9 , producing higher temperatures than these tests as expected. However comparing this case with tests 1 and 2 with the same equivalence ratio, far higher temperatures are found. This test also produces higher $\mathrm{CO}$ values at the wall, Figures 12 and 13. Inlet 2 appears to produce lower wall temperatures than when using a combination of 1 and 2 and lower $\mathrm{CO}$ values than both inlet 1 and a combination of inlet 1 and 2. The $\mathrm{CO}$ mass fraction shows higher levels of $\mathrm{CO}$ occur where high values of velocity and temperature are found, where there is greater mixing and combustion.

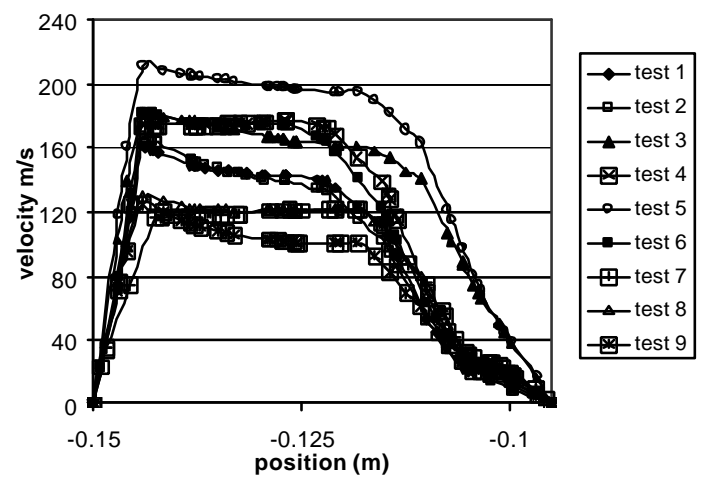

Figure 14: Velocity profiles across combustor exit in radial direction

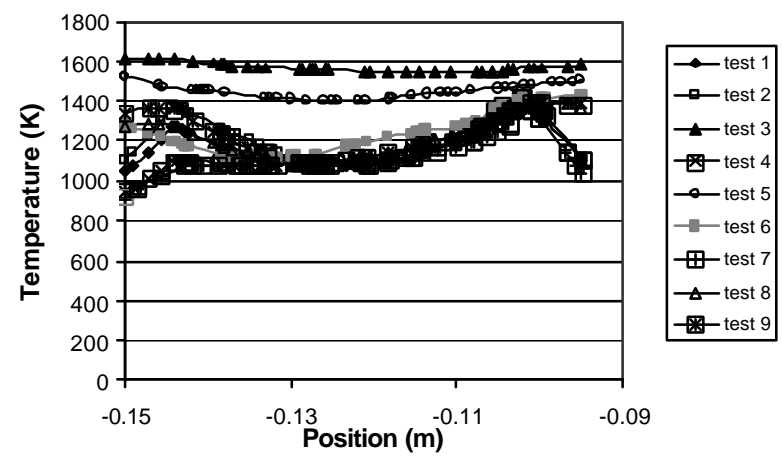

Figure 15: Temperature profiles across combustor exit in radial direction 
The exit velocities and temperatures are shown for the combustor taken radially through the centreline of the exit, Figures 14 and 15 respectively. They show that different thermal inputs (500 and $350 \mathrm{~kW}$ ) achieve the same exit temperatures when they have constant equivalence ratios (test 4-6 and 7-9). Tests 7-9 have lower exit velocities than for tests 4-6 as there is lower total mass flow at the inlet and hence have a lower thermal output. It is important to keep combustor exit temperatures constant, as this is required by turbine inlet conditions. Thus he results show the thermal input to the combustor can be varied whilst still maintaining constant exit conditions. Also small changes in the equivalence ratio (e.g. from 1.2 to 1.5 fuel lean) have only a small change in the exit temperature. The effect of varying inlet configuration to the exit shows that using air through inlet 1 gives the lowest exhaust gas temperature with an average exit velocity for the same thermal input and equivalence ratio. Using air inlet 2 or a combination of inlets 1 and 2 give higher exit temperatures and velocities. However the use of combined inlet 1 and 2 cause higher wall temperatures and higher $\mathrm{CO}$ levels. Inlet 2 appears to give the best configuration in maintaining lower wall temperatures and low $\mathrm{CO}$ levels. Most tests show that combustor exhaust gas temperatures are suitable for firing directly into the gas turbine. For cases where the gas exceeds the turbine inlet temperature, dilution air is used to lower the temperature. $\mathrm{CO}$ levels in the combustor exit were also examined. Low levels of $\mathrm{CO}$ are found in the combustor exit with values up to $20 \mathrm{ppm}$ (from mole fraction). Temperatures inside the combustor exceed $1400 \mathrm{~K}$ in the region of the main flow near the combustor walls. The highly swirling flow and length of combustion chamber will cause a long residence time. This long residence time and high temperature inside the flow will cause any tars and char particles in the flow to be fully burnt out

The refractory lining length is acceptable with most $\mathrm{CO}$ burnt out by the end of the section. Rigorous wall cooling would be provided after the refractory section on the metal surfaces. Although wall cooling would cause quenching it would not contribute to the additional formation of $\mathrm{CO}$ as nearly full burnout has occur by this point.

\section{PRESSURE DROP}

Minimising pressure drop across any system is an important consideration and the maximum values across the combustor are shown below in Table 3. Tests 4 to 6 give the largest pressure drop across the combustor. This is caused from increased inlet mass flows for these tests. Using inlet 2 for the air inlet causes the largest pressure drop across the combustor and the maximum value is found to be 0.09 bar for test 5 . This value is in an acceptable range as the gas turbine allows a pressure drop of 0.2 bar across the system. This pressure drop could be reduced further by placing a $7^{\circ}$ diffuser on the tangential off-take [19]. This could also recover up to $40 \%$ of lost kinetic energy. Another advantage of the tangential offtake is that it minimises the formation of coherent structure such as the precessing vortex core which tend to appear with conventional centrally located exhausts and free/forced tangentially velocity distributions [20].

\section{PARTICLE INJECTION}

A range of particles were introduced to the combustor through the wood gas inlet for all the cases, and are representative of those present in the gas from the gasification process. A Rosin-Rammler size distribution between 1 and 100 microns was used with an average diameter of 50 microns, Figure 16

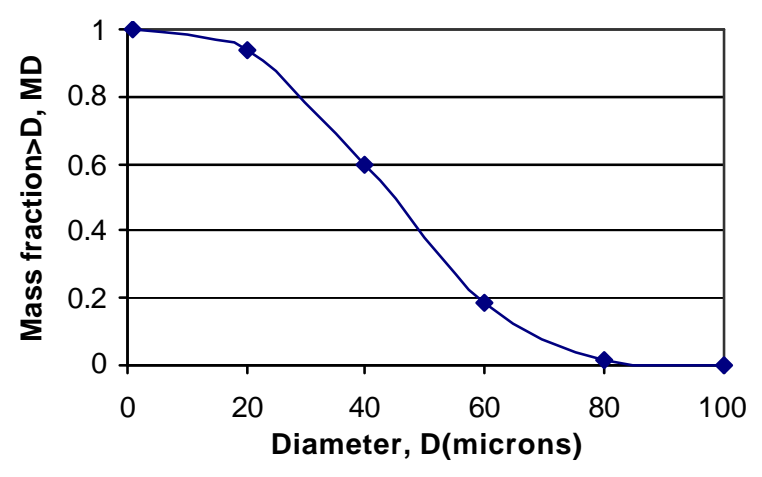

Figure 16: Rossin-Rammler distribution for wood particles

Larger particles were not introduced into the combustor as these would have been removed by earlier systems. The conical section, the collection pot, of the combustor should remove larger particles from the flow and the VCP situated just before the combustor exit should remove fine particles. The tangential off-take forming the exhaust of the combustor should draw the flow past the VCP situated just before it. The particles in the flow should shear off and be collected by the VCP. Table 3 shows the collection efficiency of the combustor.

Table 3: Particle collection efficiency and pressure drop across combustor

\begin{tabular}{l|l|l|l|l} 
Test & $\begin{array}{l}\text { Collection } \\
\text { pot } \%\end{array}$ & VCP $\%$ & Escape \% & $\begin{array}{l}\text { Static Press } \\
\text { drop }(\mathrm{Pa})\end{array}$ \\
\hline 1 & 49 & 43 & 5 & 6250 \\
\hline 2 & 69 & 16 & 12 & 6500 \\
\hline 3 & 47 & 39 & 11 & 6250 \\
\hline 4 & 7 & 69 & 21 & 8000 \\
\hline 5 & 48 & 40 & 9 & 9000 \\
\hline 6 & 27 & 48 & 22 & 8300 \\
\hline 7 & 12 & 64 & 21 & 4250 \\
\hline 8 & 50 & 21 & 26 & 4300 \\
\hline 9 & 43 & 44 & 10 & 4200
\end{tabular}

Figure 17 shows larger particles being collected in the bottom conical section of the combustor, and smaller particles collected in the VCP. 

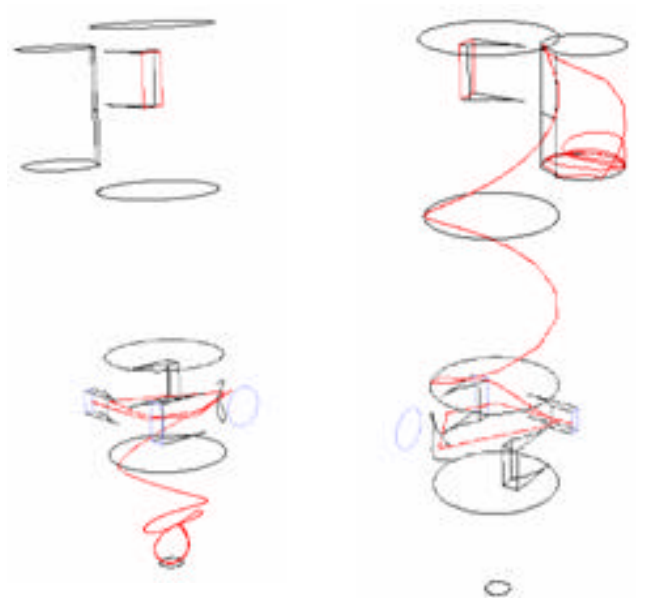

Figure 17: Particles collected in combustor for a) conical bottom section and b) VCP

Test 1 to 3 show the combustor removes more particles than most other tests. This is most likely due to the effect of the velocity patterns inside the flow and the particle loading. Different flow velocity patterns obviously effect the position and number of particles that pass the VCP. Further investigation is needed to optimise the position of the VCP for maximising the removal of particles for different tests. Most of the particles for tests 1-3 escaping the combustor are less than 5 microns. This size of particles in the exhaust gas is an acceptable value for direct feed in to the gas turbine.

\section{CONCLUSION}

The cyclone combustor runs well on LCV gas and produces a stable highly swirling flow. Good mixing and burnout occurs in the chamber with early combustion initiated near the inlets. The combustor can be run over a range of thermal inputs and equivalence ratios whilst maintaining similar exit conditions. Conditions within the combustor will burnout any tar or char particles in the flow. The maximum pressure drop across the combustor is 0.09 bar, which is an acceptable value for the system.

The inlet configuration to the combustor has an effect on the exit velocities with air inlet 2 and a combination of air inlets 1 and 2 giving the highest velocities. The use of air inlet 2 alone appeared to give the best configuration for maintaining lower wall temperatures and lower CO levels. The tangential off-take on the combustor was shown to perform well, producing good exit flow. The flow is drawn past the VCP as it is forced into the tangential off-take that forms the exhaust. This mechanism cause most fine particles in the flow to be projected into it. The VCP collected most particles down to 5 microns for test 1 to 3 , and further investigation is need to optimise the position of the VCP for different tests. The exhaust gas from the combustor is clean with low emissions and the gas is suitable for direct firing into a small-scale gas turbine. CFD results are at present being validated with experimental data.

\section{ACKNOWLEDGEMENTS}

The authors would like to thank EPSRC (contract GR/N16587/01) for their support on this work.

\section{REFERENCES}

[1] Adouane, B., Hoppesteyn, P., de Jong, W., van der Wel, M., Hein, K. R. G. and Spleithoff, H., 2002, Gas Turbine Combustor for Biomass Derived LCV gas, a First Approach towards Fuel- $\mathrm{NO}_{\mathrm{x}}$ Modelling and Experimental Validation, Applied Thermal Engineering, vol. 22, Issue 8, pp 959-970

[2] Beer, J. M., 1995, Clean Combustion in Gas Turbines: Challenges and Technical Responses -A Review, Journal of the Institute of Energy, vol. 67, pp 2-10

[3] Beer, J. M. and Garland, 1997, A Coal Fuelled Combustion Turbine Cogeneration System with Topping Combustion, Journal of Engineering for Gas Turbines and Power, vol.119, no. 1, pp 84-92

[4] Hasegawa, T, 1998, Study of Low $\mathrm{NO}_{x}$ in Medium-Btu Fuelled $1300^{\circ} \mathrm{C}$ - Class Gas Turbine Combustor in IGCC, ASME International Gas Turbine and Aeroengine Congress and Exibition, 98-GT-331, Stockholm, Sweden

[5] Hoppesteyn, P. D. J., de Jong W., Andries, J. and Hein, K. R. G., 1998, Coal Gasification and Combustion of LCV Gas, Bioresource Technology, vol. 65, no. 1-2, pp105-115

[6] Nakata, T, Sato, M., Ninomiya, T. and Hasegawa, T., 1996, Journal of Engineering for Gas Turbines and Power, vol. 118, 94-GT-218, pp $534-540$

[7] Al-Shaikhly, A. F., Mina, T. I. And Neergaard, M. O., 1994, Development of a dual fuel LBTU gas/diesel burning combustion system for a $4.2 \mathrm{MW}$ gas turbine, ASME International Gas Turbine and Aeroengine Congress and Exhibition, 94 -GT-438, The Hague, NL

[8] Neilson, C. E., Shafer, D. G. and Carpentieri, E., 1998, Gas Turbine Fuel Nozzle Design and Combustion Test Evaluation and Emission Results with Simulated Gasified wood Product Fuels, International Gas Turbine and Aeroengine Congress and Exhibition, Stockholm, Sweden,

[9] Neilson, C., 1998, Gas Turbine Modifications for Biomass Fuel Operation, Biomass and Bioenergy, Vol. 15, No. 3, pp269273

[10] Battista, R. A., Feitelberg, A. S and Lacey, M. A., 1996, Design and Performance of Low Heating Value Fuel Gas Turbine Combustors, ASME International Gas Turbine and Aeroengine Congress and Exhibition, 96-GT-531, Birmingham, UK

[11] Battista, R. A. and Farrell, R. A., 1979, Development of an Industrial Gas Turbine Combustor Burning a variety of Coat Derived Low Btu Fuels and Distillate, ASME, 79-GT-172

[12] Lawson, C. C, 1985, Water-Cooled Components Test Program, Final Report, DOE/MC/20192-1953, Contract DEAC21-83MC20192

[13] Beede, K. W. and Blanton, J. C., 1979, Development of an Industrial Gas Turbine Combustor Burning a Variety of CoalDerived Low Btu Fuels and Distillate, ASME paper No. 79GT-172

[14] Savelli, J. F. and Touchton, G. L., 1985, Developement of a Gas Turbine Combustion System for Medium-Btu Fuel, ASME Paper No. 85-GT-98

[15] Constant, D. R., Cannon, M. F. and Kelsall, G. J., 1997, Development of an LCV Fuel Gas Combustor for an Industrial Gas Turbine, 1997, International Gas Turbine and Aeroengine Congress and Exhibition, ASME, 97-GT-38 
[16] Craig, J. D. and Purvis, C. R., 1999, A Small Scale Biomass Fueled Gas Turbine Engine, Transactions of the ASME, Vol. 121, January, pp 64-67

[17] Fraser, T, 2003, CFD Modelling of an Inverted Cyclone Gasifier, PhD Thesis, Cardiff University, UK

[18] Syred, C., Griffiths, A. J. and Syred, N., 2004, Combustor Development for Dual Fuel Combustion with Gas Ol and Biomass Gasification Products, AIAA paper 2004-140, $42^{\text {nd }}$ AIAA Aerospace Science Meetings and Exhibit

[19] O'Doherty, T., Biffin, M. and Syred, N., 1992, The Use of Tangential Offtakes for Energy Savings in Process Industries, Proceedings of the Institute of Mechanical Engineers, Vol. 206, pp 99-109

[20] Gupta, A., Lilley, D., Syred, N. Swirl Flows, Abacus Press, Tunbridge Wells, 1984 